Research Article

\title{
Antimicrobial Resistance among Pregnant Women with Urinary Tract Infections Attending Antenatal Clinic at Levy Mwanawasa University Teaching Hospital (LMUTH), Lusaka, Zambia
}

\author{
Kekelwa Inyambo Yeta $\left(\mathbb{D},{ }^{1,2}\right.$ Charles Michelo ${ }^{(D)},{ }^{1,3}$ and Choolwe Jacobs ${ }^{1}{ }^{1}$ \\ ${ }^{1}$ School of Public Health, Department of Epidemiology and Biostatistics, University of Zambia, Lusaka, Zambia \\ ${ }^{2}$ Levy Mwanawasa University Teaching Hospital, P. O. Box 810034, Lusaka, Zambia \\ ${ }^{3}$ Strategic Centre for Health Systems Metrics \& Evaluations (SCHEME), School of Public Health, \\ University of Zambia, Lusaka, Zambia
}

Correspondence should be addressed to Kekelwa Inyambo Yeta; k.yeta@yahoo.com

Received 15 July 2020; Revised 1 November 2020; Accepted 10 February 2021; Published 4 March 2021

Academic Editor: Faham Khamesipour

Copyright (C) 2021 Kekelwa Inyambo Yeta et al. This is an open access article distributed under the Creative Commons Attribution License, which permits unrestricted use, distribution, and reproduction in any medium, provided the original work is properly cited.

\begin{abstract}
Introduction. Globally, there is a growing concern over antimicrobial resistance (AMR) which is currently estimated to account for more than 700,000 deaths per year worldwide. AMR undermines the management of infectious diseases in general especially in pregnancy where significant bacteriuria continues to be a serious cause of maternal and perinatal morbidity and mortality. We therefore aimed to determine the prevalence of AMR and the associated factors among pregnant women with urinary tract infections (UTIs) attending antenatal clinic at a selected hospital in Lusaka, Zambia. Methods. This was a hospital-based, crosssectional study conducted between November 2018 and May 2019. Interviewer-administered questionnaire was used to assess the sociodemographic characteristics and behavioural characteristics. Laboratory tests were also conducted. Descriptive statistics of study participants were used to describe the characteristics of the respondents. Chi-square was used to assess the association between categorical variables. The logistic regression analysis was carried out to generate the adjusted odds ratio with $95 \%$ confidence interval. Results. Overall $(n=203)$, the prevalence of UTI was 60\% (95\% CI: 53.3\%-66.7\%). The most isolated bacteria were E. coli (59\%) and Klebsiella (21\%). The prevalence of AMR was found to be 53\% (95\% CI: $46.1 \%-59.8 \%)$. The drugs highly resistant to antimicrobials were nalidixic acid (88.3\%), ampicillin (77.8\%), and norfloxacin (58.5\%), while the least resistant drug was chloramphenicol (20\%). There were no important significant predictors to AMR among pregnant women observed in this study. Conclusion. We found high burden of AMR closely linked to observe high prevalence of UTI suggested in this small population. This suggests a need to develop integrated surveillance systems that aim for early and regular screening of pregnant women for UTI as well as concurrent determination of antibiotic susceptibility patterns. This is important to prevent complications that may endanger maternal and fetal health outcomes. Furthermore, further research is needed to explore reasons for this high prevalence of AMR including examining possible attribution to the misuse of drugs so as to inform, enforce, or adjust the prescription-only policies and enforce antimicrobial stewardship programs.
\end{abstract}

\section{Introduction}

It is estimated that, about 150 million people worldwide are diagnosed with urinary tract infections (UTIs) [1]. Urinary tract infections are among the most common bacterial infections encountered by both the general community and in hospitals, ranking the second commonest infection after respiratory infections [2]. In poor-resourced and tropical countries, UTIs are still the major source of morbidity and death [3] with an estimated annual global incidence of at least 250 million in developing countries [4]. Women are more susceptible to UTI when compared to men, and this is largely due to short urethra, absence of prostatic secretion, pregnancy, and easy contamination of the urinary tract with 
faecal flora [5]. About 50\% of women will suffer from at least one urinary tract infection (UTI) during their adult life including during pregnancy. There are many different pathogenic microorganisms (bacteria, fungi, protozoa, and viruses) which cause UTIs among pregnant women. Among the bacterial pathogens, E. coli and other Enterobacteriaceae are the most and account approximately $75 \%$ of the isolates [4].

Antibiotics are among the most commonly used medications to treat UTIs globally and are of enormous importance to global health. Despite their importance, the sustained effectiveness of antibiotics is endangered by the development of resistance. The excessive and unnecessary use of antibiotics has been the main cause of antibiotic resistance [6]. Internationally, there is a growing concern over antimicrobial resistance (AMR) which is currently estimated to account for more than 700,000 deaths per year worldwide [7]. Antimicrobial resistance is a broad term that includes resistance to all antimicrobial agents. Antimicrobial resistance results in the therapeutic failure of standard treatment and longer duration of treatment, leading to an increased risk in the spread of infections [8]. One of the important risk factors for antibiotic resistance is the abuse of antibiotics by the public [9], while some studies have also reported that some pregnant women are ignorant of the management of common infections which results in AMR [10].

In Zambia, like many other countries, there is emerging evidence of AMR in several pathogens [11-13]. Despite the large number of antimicrobial agents available, UTIs have remained a significant problem among pregnant women in Zambia [14], particularly in Lusaka. Yet, evidence on the prevalence of AMR among pregnant women and the associated factors is limited. It is against this background that the study was carried out to determine the prevalence of AMR and associated factors among pregnant women with UTI and attending antenatal clinic at a selected university teaching hospital in Lusaka, Zambia.

\section{Methods}

2.1. Study Setting and Period. A hospital-based cross-sectional study based on quantitative approach was conducted from November 2018 to May 2019. The study was conducted at Levy Mwanawasa University Teaching Hospital, located in Lusaka, the capital city of Zambia. The selected teaching hospital serves as a referral centre with a total catchment population of approximately 800,000 in- and outpatients.

2.2. Study Participants and Sampling. This study focused on all pregnant women who were attending antenatal clinic at Levy Mwanawasa University Teaching Hospital. All pregnant women aged 18 years and above, attending antenatal clinic within the data collection period, were targeted for the study, and they were hence purposely selected. Participants consenting to participate in the study were included in the study. We excluded pregnant women who were on antimicrobial therapy for UTI two weeks prior to selection and who provided inadequate urine samples (less than $10 \mathrm{ml}$ urine), whose urine specimens were collected more than 2 hours before receipt for laboratory diagnosis, with specimens submitted in leaking or dirty unsterile containers and specimens revealing growth of more than two types of bacteria on culture.

2.3. Study Design. This was a hospital-based, cross-sectional study conducted between November 2018 and May 2019. Interviewer-administered questionnaire was used to assess the sociodemographic characteristics and lifestyle data. Laboratory tests were also conducted. Descriptive statistics of study participants were used to describe the characteristics of the respondents. Chi-square was used to assess the association between categorical variables. The logistic regression analysis was carried out to generate the adjusted odds ratio with $95 \%$ confidence interval.

2.4. Sample Size. The sample size was determined by using the single size population proportion formula with an assumption of $14 \%$ prevalence of antimicrobial resistance, from a study by Behailu Deres et al. [14]. Therefore, for 0.14, p, $1.96 Z, 95 \% \mathrm{CI}, a=0.05$, and a $10 \%$ nonresponse rate, a sample size of 203 participants was determined. A convenient sampling technique was used to enroll consecutive pregnant women attending antenatal care in the hospital during the study period. Patients who tested positive for UTIs were recruited until the expected number of participants of the study sample was attained.

The main outcome variable was antimicrobial resistance, in pregnant women, a binary variable. Independent variables included sociodemographic characteristics (age, marital status, residence, education level, and monthly income) and clinical characteristics (HIV status, history of urinary tract infection, and trimester).

2.5. Laboratory Procedures. Urine specimens were inoculated onto CLED (cysteine-lactose-electrolyte-deficient agar) and MacConkey's and blood agar plates (OXOID, Ltd, Basingstoke, UK) by using the streak method following the standard microbiological procedures. The plates were incubated at $37^{\circ} \mathrm{C}$ for 24 hours and then examined for significant growth. Diagnosis of UTI was based on the presence of $\geq 10^{5}$ colony-forming units per millilitre of midstream urine of one or two types of bacterial species. Specimens with more than two types of bacteria species were regarded as contamination, and sample collection was repeated. The identification of bacteria isolate was done using biochemical tests.

Antimicrobial susceptibility testing was performed for the bacterial isolates identified from urine cultures with significant growth by using the Kirby-Bauer disk diffusion method on Mueller-Hinton agar (Oxoid Ltd, Basingstoke, UK) according to the criteria set by the Clinical and Laboratory Standards Institute $[15,16]$ to determine the susceptibility patterns of the commonly used antibiotics. 
The procedure for antimicrobial susceptibility testing was as follows. In brief, 4-6 morphologically identical colonies of bacteria from pure cultures were collected with an inoculating loop, transferred into a tube containing $5 \mathrm{~mL}$ of nutrient broth, then mixed gently until a homogenous suspension was formed, and incubated at $37^{\circ} \mathrm{C}$ for $3-5$ hours until the turbidity of the suspension became adjusted to the density of $0.5 \mathrm{McF}$ arland standards, which yields a uniform suspension containing 105-106 cells/mL.

Using a sterile nontoxic dry cotton swab, the sample of the standardized inoculums (turbidity was adjusted to obtain confluent growth) were taken and streaked on the entire surface of the dried Mueller-Hinton agar plate three times, turning the plate at $60^{\circ}$ angle between each streaking to ensure even distribution. The inoculum was allowed to dry for 5-15 minutes with the lid in place. Using standard antibiotic disks (Oxoid) containing nalidixic acid $(30 \mu \mathrm{g})$, nitrofurantoin $(300 \mu \mathrm{g})$, norfloxacin $(10 \mu \mathrm{g})$, chloramphenicol $(30 \mu \mathrm{g})$, co-trimoxazole $(25 \mu \mathrm{g})$, cefotaxime $(30 \mu \mathrm{g})$, penicillin $(10 \mu \mathrm{g}))$, gentamicin $(10 \mu \mathrm{g}))$, erythromycin $(15 \mu \mathrm{g}))$, ciprofloxacin $(5 \mu \mathrm{g})$, ampicillin $(10 \mu \mathrm{g}))$, and vancomycin $(30 \mu \mathrm{g})$ were dispensed onto well-labelled inoculated MHA plates using the disc dispenser. Sterile antibiotic disks used were based on their availability at the laboratory at the time of the study. The plates were allowed to stand for few minutes and were incubated at $37^{\circ} \mathrm{C}$ for 24 hours within 15 minutes of applying. Antibiotic sensitivity was checked by measuring the zone of inhibition (zone of clearance) from the back of the plate to the nearest $\mathrm{mm}$ using a ruler or caliper. Sterile zone of inhibitions was recorded and used to establish if the bacterial isolates were resistant, intermediate, and susceptible using reference books and WHONET. Bacteria were reported as sensitive (S), intermediate (I), or resistant $(\mathrm{R})$ to each of the antibiotics used in the test.

2.6. Data Processing, Quality Control, and Analysis. Data were collected by face-to-face interviews using a standard questionnaire to collect sociodemographic and lifestyle data from the participants. The questionnaire was designed in English and translated to Nyanja, a commonly used local language in Lusaka. The tool was pretested for validation. Upon completion of the interview, the participants were sent to the hospital laboratory with a request form. Instructions were given to them by a trained medical laboratory personnel on how to collect the urine specimen. Participants were advised to place $10-20 \mathrm{~mL}$ clean-catch midstream urine specimen into a sterile screw-capped, wide-mouthed, sterile disposable plastic container after signing the consent form [15]. Each sample bottle was labelled with date and time of collection and then immediately sent to the microbiology department for microscopy, culture, and antimicrobial susceptibility. A unique sample number was linked to the participant's questionnaire which was in turn linked to confidential patient information.

Data collected were verified for completeness and were double-entered into the excel spreadsheet to ensure accuracy and reliability. Culture and biochemical tests were performed by a laboratory scientist using the standard operating procedures to ensure quality results. The American Type Culture Collection (ATCC) reference strains such as Escherichia coli (ATCC-25922), Staphylococcus aureus (ATCC-25923), and Pseudomonas aeruginosa (ATCC-27853) were used as quality control parameters of laboratory tests.

The culture results from the samples collected were used to calculate prevalence of UTI, to characterize the type of microbial growth (isolates), and to test for antimicrobial susceptibility test. The data generated from the questionnaires were entered and checked for completeness, consistency, and accuracy and then entered into an Excel spreadsheet. After manual verification and cleaning, the data processing and statistical analysis was performed using STATA software version 14.0 (Stata ${ }^{\mathrm{TM}}$ Corporation, Texas, USA).

Basic descriptive statistics (proportions and means) of study participants were used to describe the characteristics of the variables of respondents. Categorical variables were summarized in the form of numbers and percentages and presented in table format. Continuous variables such as age were assessed for normality assumptions using Q-Q plots. Statistics such as means and their respective standard deviations were reported. Chi-square test was used to assess statistical differences between categorical variables with significance level set at $p<0.05$ and $95 \%$ confidence interval. Bivariate analysis was applied, and all the variables with a $p$ value less than 0.05 were then entered into the logistic regression model to generate the adjusted odds ratio with $95 \%$ confidence interval. A $p$ value less than $0.05(p<0.05)$ was considered statistically significant.

2.7. Ethical Consideration. This study obtained ethical approval from the University of Zambia Biomedical Research Ethics Committee (UNZABREC) (reference number: 00209-18). Authority to conduct the study was also obtained from the National Health Research Authority in Zambia. We received written informed consent from the study participants. Confidentiality was maintained by omitting personal identifiers. Privacy was also maintained.

\section{Results}

3.1. Participant Description. A total of 203 pregnant women were included in this study. As shown in Table 1, most of the pregnant women were married with a proportion of $80.9 \%$ (165/206). A majority of the study participants were in the age range of 25 to 29 years and 30 to 34 (59\% and $28.8 \%$ ) respectively. Most of these women came from low-cost areas (areas with high population density and low cost of living) having a proportion of $68.2 \%(131 / 206)$, and 52\% (102/202) of the women had secondary education as the highest level of education achieved. Approximately 61\% (125/202) of the women had a history of previous urinary tract infection, and half of them $(50 \%)$ were in their second trimester.

3.2. Prevalence of Urinary Tract Infection. The prevalence of urinary tract infection among pregnant women who were attending antenatal clinic at Levy Mwanawasa University Teaching hospital was found to be $60 \%$ (95\% CI: $53.3 \%-$ $66.7 \%)$. 
TABLE 1: Sociodemographic characteristics of study participants at Levy Mwanawasa University Teaching Hospital $(n=203)$.

\begin{tabular}{|c|c|c|}
\hline \multirow{2}{*}{ Characteristics } & \multicolumn{2}{|c|}{ Total $(n=203)$} \\
\hline & Patients $(n)$ & Percentage (\%) \\
\hline \multicolumn{3}{|l|}{ Marital status } \\
\hline Single & 36 & 17.6 \\
\hline Married & 163 & 80.9 \\
\hline Separated & 1 & 0.4 \\
\hline Widowed & 1 & 0.4 \\
\hline Divorced & 2 & 1.0 \\
\hline \multicolumn{3}{|l|}{ Age in years } \\
\hline Less than 20 & 9 & 4.3 \\
\hline 20 to 24 & 43 & 20.0 \\
\hline 25 to 29 & 59 & 28.8 \\
\hline 30 to 34 & 59 & 28.8 \\
\hline 35 to 39 & 24 & 12.7 \\
\hline 40 and above & 9 & 4.4 \\
\hline \multicolumn{3}{|l|}{ Residence } \\
\hline High cost & 15 & 7.8 \\
\hline Low cost & 131 & 68.2 \\
\hline Medium cost & 46 & 23.0 \\
\hline \multicolumn{3}{|l|}{ Education level } \\
\hline Primary & 28 & 14.3 \\
\hline Secondary & 102 & 52.0 \\
\hline Tertiary & 66 & 33.7 \\
\hline \multicolumn{3}{|c|}{ Monthly income (USD) } \\
\hline No income & 48 & 23.4 \\
\hline 10.1 to 15 & 42 & 20.5 \\
\hline 15.1 to 20 & 26 & 12.7 \\
\hline 20.1 to 30 & 50 & 24.4 \\
\hline Above 30 & 39 & 19.0 \\
\hline \multicolumn{3}{|l|}{ HIV status } \\
\hline Reactive & 74 & 36.8 \\
\hline Nonreactive & 127 & 63.2 \\
\hline \multicolumn{3}{|c|}{ History of urinary tract infection } \\
\hline Yes & 125 & 61.0 \\
\hline No & 78 & 39.0 \\
\hline \multicolumn{3}{|c|}{ Pregnancy trimester } \\
\hline First & 19 & 10.8 \\
\hline Second & 88 & 50.0 \\
\hline Third & 69 & 39.2 \\
\hline
\end{tabular}

The following bacterial uropathogens were identified: E. coli, 59 isolates (28\%); S. aureus, 17 isolates (8.29\%); Klebsiella pneumoniae, 21 isolates (10.24\%); Enterobacter spp., 12 isolates (5.85\%); Proteus spp., 5 isolates (2.44\%); Pseudomonas spp., 3 isolates (1.46\%), and Streptococcus spp., 5 isolates $(2.44 \%)$, and the least isolates were E. agglomerans, 1 isolate (0.49\%), and Shigella, $1(0.49 \%)$ (Figure 1).

3.3. Prevalence of ANC-Based AMR. Out of 123 cases with significant bacteria growth, 65 (53\%, 95\% CI: 46.1\%-59.8\%) cultures plates were resistant to one or more drugs used in this study and 58 (47\%, 95\% CI: $46.1 \%-53.9)$ were susceptible to all the drugs.

The prevalence of resistance in descending order was as follows: nalidixic acid, $88.3 \%$; ampicillin, $77.8 \%$; norfloxacin, $58.5 \%$; vancomycin, $50 \%$; penicillin, $50 \%$; co-trimoxazole, $47.6 \%$; erythromycin, $44.4 \%$; gentamicin, $41.2 \%$;

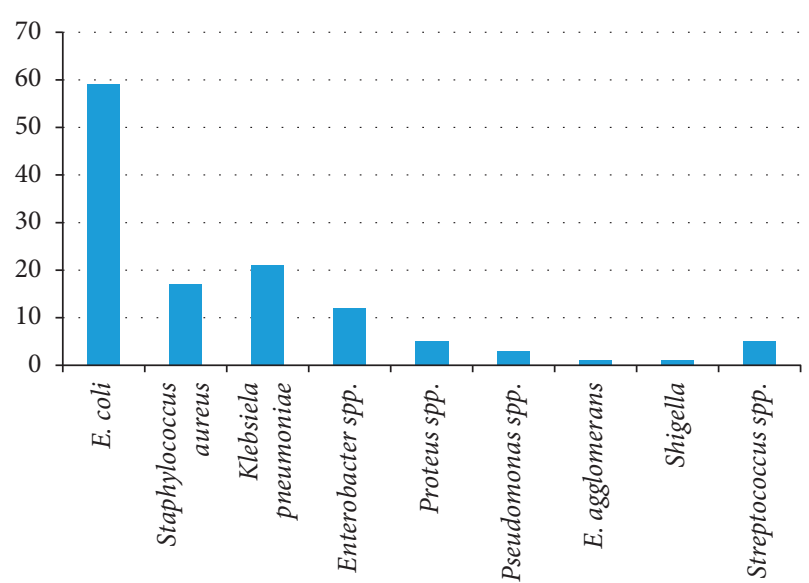

FIgURE 1: Prevalence of microorganism isolates.

nitrofurantoin, 40.5\%; ciprofloxacin, 37.5 ; cefotaxime, $20 \%$; and chloramphenicol, 20\% (Figure 2).

\subsection{Resistance Patterns according to Isolates}

3.4.1. Factors Associated with Antimicrobial Resistance. To determine the association between the dependent variable (antimicrobial resistance) and explanatory variables (age, current use of antibiotics, HIV status, duration of antibiotic use, symptoms, history of UTI infection, trimester, residence, and marital status), the univariate and multivariate binary logistic regression analyses were carried out. In the univariate analysis, history of antibiotic use $(\mathrm{OR}=1.19,95 \% \mathrm{CI}$ : 0.38 , 3.75; $p<0.770$ ) had an increased likelihood of antimicrobial resistance compared to those who did not use antibiotics in the past. Similarly, the secondary and tertiary maternal education $(\mathrm{OR}=1.95,95 \% \mathrm{CI}: 0.64,5.94 ; p<0.24$ and $\mathrm{OR}=1.23,95 \%$ CI: $0.39,3.86 ; p<0.73$, respectively) had an increased likelihood of antimicrobial resistance than the maternal primary education, while married women had a decreased likelihood of antimicrobial resistance compared to those who were single $(\mathrm{OR}=0.58,95 \% \mathrm{CI}: 0.20,1.71$; $p<0.32)$. However, all these findings were not significantly associated with AMR.

The results from the multivariate analysis showed that that current use of antibiotics reduced the likelihood of antimicrobial resistance compared to those not using antibiotics currently (AOR $=0.50,95 \% \mathrm{CI}: 0.13,1.94 ; p<0.31)$. Increased maternal age reduced the likelihood of antimicrobial resistance compared to women aged 18 to 24 . The underlying and proximate determinants of antimicrobial resistance are shown in Table 1. From our study findings, it was noticed that most of the independent variables did not play a significant role in influencing antimicrobial resistance in pregnant women attending at antenatal at LMUTH (Tables 2-4).

\section{Discussion}

We have found the prevalence of urinary tract infection to be $60 \%$ among pregnant women with urinary tract infections (UTIs) attending antenatal clinic at a selected hospital in 


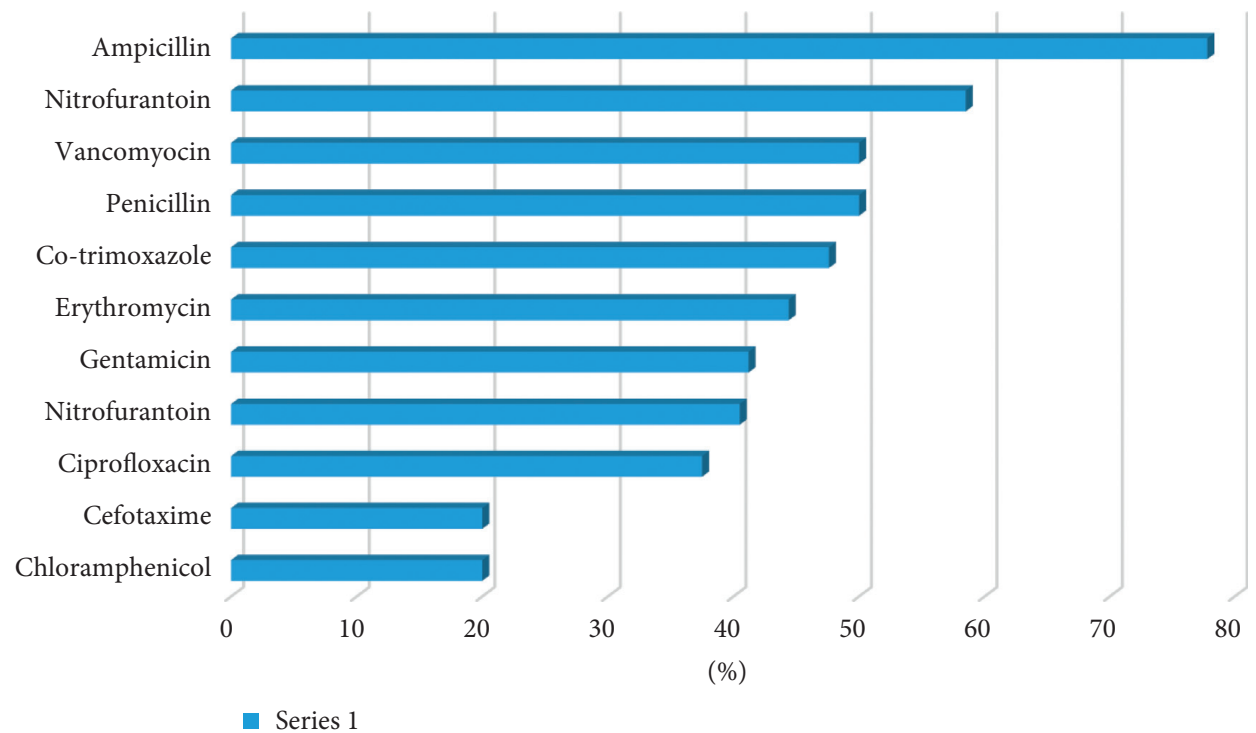

FIGURE 2: Resistance to antibiotics among pregnant women at LMUTH.

TABLe 2: Susceptibility patterns of Staphylococcus aureus.

\begin{tabular}{lcccc}
\hline Antibiotics tested & \multicolumn{2}{c}{ Staphylococcus aureus $(n=50)$} & \multicolumn{2}{c}{ Streptococcus spp. (n=10) } \\
& Total & Resistance $(n \%)$ & Total & 2 \\
Resistance $n(\%)$
\end{tabular}

Lusaka, Zambia. The main causative pathogens for the UTIs were E. coli and Klebsiella. These results are consistent with studies conducted in Libya $[17,18]$ which found E. coli and Klebsiella as the highest isolated bacteria. The prevalence of AMR was found to be $53 \%$ with the highest resistant drugs being ampicillin, nalidixic acid, and norfloxacin. The least resistant were found to be chloramphenicol and nitrofurantoin. Our results of AMR are similar to a study conducted in Libya, [15] which found the AMR prevalence of between $10.5 \%$ and $64.5 \%$ with high levels of resistance to ampicillin, and Australia [19], with low levels of resistance for nitrofurantoin. Our study further determined both demographic and clinical predictors of AMR, which, however, showed no significant statistical association with the outcome variable. All the sociodemographic variables had $p$ values greater than 0.05 , similar to a study conducted in Ethiopia, [20] where they did not find any sociodemographic predictor variables for AMR, except for clinical and bacterial variables.

Urinary tract infections (UTIs) are the most widely spread infections seen in hospital settings and the second commonest infection seen in the general population [21].
The main findings of this study were prevalence of urinary tract infections, at $60 \%$. These results are similar to other studies conducted in Ebonyi state, Nigeria [22], and in India [23] which had a prevalence of 55\% and 61\%, respectively. Our observation of the high prevalence found in this study highlights the burden of the problem which could be related to poor personal hygiene for some women as a result of vaginal anatomical and functional changes and challenges for some women in maintaining personal hygiene during pregnancy $[24,25]$ including the socioeconomic status of some women $[26,27]$. Importantly, the high prevalence of urinary tract infections observed in this study is a concern due to the many adverse implications it has on pregnant women such as poor maternal and perinatal outcomes, sepsis, caesarean delivery, and preterm birth [28, 29].

We have also found that the three most prominent bacteria isolated among the participants were E. coli (28.78\%), Staphylococcus aureus (8.29\%), and Klebsiella pneumoniae $(10.24 \%)$ of which $E$. coli was the most predominant. The least isolated bacteria were Shigella $(0.49 \%)$ and E. agglomerans (0.24\%). These results are comparable 
TABLE 3: Susceptibility patterns of Gram-negative isolates.

\begin{tabular}{|c|c|c|c|c|}
\hline \multirow{2}{*}{ Antibiotics tested } & \multicolumn{2}{|c|}{ E. $\operatorname{coli}(n=126)$} & \multicolumn{2}{|c|}{ Klebsiella $(n=54)$} \\
\hline & Total & Resistance $(n \%)$ & Total & Resistance $n(\%)$ \\
\hline Nitrofurantoin & 38 & $14(37 \%)$ & 16 & $8(50 \%)$ \\
\hline Nalidixic & 2 & $1(50 \%)$ & 17 & $14(82 \%)$ \\
\hline Chloramphenicol & 15 & $3(20 \%)$ & 1 & $0(0 \%)$ \\
\hline Norfloxacin & 27 & $14(52 \%)$ & 9 & $6(67 \%)$ \\
\hline Co-trimoxazole & 7 & $4(57 \%)$ & 3 & $2(67 \%)$ \\
\hline Ciprofloxacin & 15 & $7(47 \%)$ & 4 & $3(75 \%)$ \\
\hline Cefotaxime & 9 & $2(22 \%)$ & - & Drug not given \\
\hline Gentamicin & 7 & $1(14 \%)$ & 2 & $2(100 \%)$ \\
\hline Penicillin & 2 & $1(50 \%)$ & - & Drug not given \\
\hline Ampicillin & 3 & $2(67 \%)$ & 2 & $2(100 \%)$ \\
\hline Erythromycin & 1 & $0(0 \%)$ & - & Drug not given \\
\hline \multirow{2}{*}{ Antibiotics tested } & \multicolumn{2}{|c|}{ Enterobacter spp. $(n=29)$} & \multicolumn{2}{|c|}{ Proteus spp. $(n=17)$} \\
\hline & Total & Resistance $(n \%)$ & Total & Resistance $n(\%)$ \\
\hline Nitrofurantoin & 10 & $3(30 \%)$ & 4 & $1(25 \%)$ \\
\hline Nalidixic & 10 & $9(90 \%)$ & 4 & $4(100 \%)$ \\
\hline Chloramphenicol & 2 & $0(0 \%)$ & 1 & $0(0 \%)$ \\
\hline Norfloxacin & 3 & $2(67 \%)$ & 4 & $3(75 \%)$ \\
\hline Co-trimoxazole & 1 & $0(0 \%)$ & 1 & $0(0 \%)$ \\
\hline Ciprofloxacin & 3 & $0(0 \%)$ & - & Drug not given \\
\hline Cefotaxime & - & Drug not given & - & Drug not given \\
\hline Gentamicin & - & Drug not given & 1 & $1(100 \%)$ \\
\hline Penicillin & - & Drug not given & - & Drug not given \\
\hline Ampicillin & - & Drug not given & 1 & $1(100 \%)$ \\
\hline Erythromycin & - & Drug not given & 1 & $0(0 \%)$ \\
\hline \multirow{2}{*}{ Antibiotics tested } & \multicolumn{2}{|c|}{ Pseudomonas $(n=18)$} & \multicolumn{2}{|c|}{ E. agglomerus $(n=3)$} \\
\hline & Total & Resistance $(n \%)$ & Total & Resistance $n(\%)$ \\
\hline Nitrofurantoin & 3 & $2(67 \%)$ & 1 & $1(100 \%)$ \\
\hline Nalidixic & 3 & $2(67 \%)$ & 1 & $1(100 \%)$ \\
\hline Chloramphenicol & - & Drug not given & - & Drug not given \\
\hline Norfloxacin & 4 & $2(50)$ & 1 & $1(100 \%)$ \\
\hline Co-trimoxazole & 7 & $3(43 \%)$ & - & Drug not given \\
\hline Ciprofloxacin & 1 & $0(0 \%)$ & - & Drug not given \\
\hline Cefotaxime & - & Drug not given & - & Drug not given \\
\hline Gentamicin & - & Drug not given & - & Drug not given \\
\hline Penicillin & - & Drug not given & - & Drug not given \\
\hline Ampicillin & - & Drug not given & - & Drug not given \\
\hline Erythromycin & - & Drug not given & - & Drug not given \\
\hline
\end{tabular}

with studies carried out in Ethiopia [30], Libya [17], and Nigeria [31], which had higher isolates of E. coli and Klebsiella, although contrary to results from studies carried out in Brazil [32] and India [23] which showed Staphylococcus aureus as the most isolated bacteria. The similarities and differences in the type and distribution of uropathogens show a discrepancy from country to country due to many factors such as environmental conditions, health practices, patient conditions, personal hygiene, number of patients examined, and laboratory procedures [15]. Finding that E. coli is still the main causative agent of UTI in pregnant women could be explained by the fact that it is a normal flora in the lower gastrointestinal tract, although its implication is a concern as it causes diarrhoea, a threat for dehydration in pregnant women $[33,34]$.

The prevalence of the resistance of the different drugs was determined and indicated quite high level of resistance for drugs such as ciprofloxacin and chloramphenicol that are commonly prescribed. The observed high level of resistance could probably be because they have been on the market for a long time, thus allowing time for microorganisms to develop resistance mechanisms towards the antibiotics [35-37]. In addition to this, this level of resistance could be attributed to easy access to antibiotics over the counter in developing countries like Zambia [35]. Additionally, the initial use of antibiotics before the laboratory results of antimicrobial susceptibility can be an attribution to the high resistance levels. Consequently, the need for the development and enforcement of antibiotic policies and proper antibiotic stewardship in developing countries cannot be overemphasized.

Our study points out that nitrofurantoin was more susceptible to uropathogens than the most commonly prescribed drugs, and this is interesting considering the fact that there have been debates to have it phased out. Literature study reviews that there is a need to resurface old drugs as they would actually be more effective, some of these drugs such as nitrofurantoin and fosfomycin, i.e., specifically for resistant uropathogens [19].

Furthermore, determinants of antimicrobial resistance were analysed, and it was found that there was no statistical significance associating the socialdemographic and clinical 
TABLE 4: Multivariant determinants of antimicrobial resistance.

\begin{tabular}{|c|c|c|c|c|}
\hline Predictors & Crude odds ratio $(95 \% \mathrm{CI})$ & $p$ value & Adjusted odds ratio $(95 \% \mathrm{CI})$ & $p$ value \\
\hline \multicolumn{5}{|l|}{ Age group } \\
\hline $18-24$ & 1 & & & \\
\hline $25-29$ & $0.96(0.32-2.81)$ & 0.920 & $0.79(0.17-3.72)$ & 0.765 \\
\hline $30-34$ & $1.05(0.35-3.18)$ & 0.931 & $0.82(0.14-4.69)$ & 0.827 \\
\hline$>35$ & $0.44(0.14-1.40)$ & 0.163 & $0.15(0.02-1.04)$ & 0.055 \\
\hline \multicolumn{5}{|l|}{ Marital status } \\
\hline Single & 1 & 0.324 & 1 & \\
\hline Married & $0.58(0.20-1.71)$ & & $0.44(0.07-2.65)$ & 0.368 \\
\hline \multicolumn{5}{|l|}{ Education } \\
\hline Primary & 1 & & 1 & \\
\hline Secondary & $1.95(0.64-5.94)$ & 0.239 & $3.20(0.55-18.4)$ & 0.195 \\
\hline Tertiary & $1.23(0.39-3.86)$ & 0.726 & $1.94(0.28-13.7)$ & 0.505 \\
\hline \multicolumn{5}{|l|}{ Trimester } \\
\hline $1^{\text {st }}$ & 1 & & 1 & \\
\hline $2^{\text {nd }}$ & $0.38(0.10-1.47)$ & 0.160 & $0.61(0.11-3.34)$ & 0.572 \\
\hline $3^{\text {rd }}$ & $0.48(0.12-1.93)$ & 0.299 & $0.68(0.10-4.72)$ & 0.695 \\
\hline \multicolumn{5}{|l|}{ Residence } \\
\hline High density & 1 & & 1 & \\
\hline Medium density & $0.70(0.28-1.73)$ & 0.438 & $1.52(0.35-6.52)$ & 0.574 \\
\hline Low density & $0.72(0.26-1.98)$ & 0.523 & $0.52(0.10-2.79)$ & 0.449 \\
\hline \multicolumn{5}{|l|}{ History of UTI } \\
\hline No & 1 & & & \\
\hline Yes & $1.19(0.38-3.75)$ & 0.770 & $2.86(0.13-61.2)$ & 0.502 \\
\hline \multicolumn{5}{|l|}{ HIV status } \\
\hline Negative & 1 & & 1 & \\
\hline Positive & $1.29(0.59-2.85)$ & 0.524 & $2.60(0.68-9.88)$ & 0.162 \\
\hline \multicolumn{5}{|l|}{ Income } \\
\hline Low $(0-1500)$ & 1 & & 1 & \\
\hline Medium (1500-3000) & $1.03(0.44-2.40)$ & 0.950 & $0.62(0.14-2.80)$ & 0.538 \\
\hline High $(\geq 3000)$ & $0.77(0.26-2.32)$ & 0.647 & $0.56(0.07-4.27)$ & 0.578 \\
\hline \multicolumn{5}{|l|}{ Kidney infection } \\
\hline No & 1 & & 1 & \\
\hline Yes & $0.27(0.04-1.69)$ & 0.161 & $0.29(0.03-3.35)$ & 0.321 \\
\hline \multicolumn{5}{|l|}{ Duration of antibiotic use } \\
\hline 7 days & 1 & & 1 & \\
\hline 14 days & $0.88(0.33-2.31)$ & 0.794 & $0.78(0.20-3.06)$ & 0.725 \\
\hline \multicolumn{5}{|l|}{ Current use of antibiotics } \\
\hline No & 1 & & 1 & \\
\hline Yes & $0.89(0.35-2.30)$ & 0.815 & $0.50(0.13-1.94)$ & 0.313 \\
\hline \multicolumn{5}{|l|}{ Symptoms } \\
\hline Dysuria/nocturia/urgency & 1 & & 1 & \\
\hline Dysuria & $1.11(0.47-2.64)$ & 0.816 & $1.00(0.28-3.64)$ & 0.998 \\
\hline Haematuria & $1.16(0.35-3.87)$ & 0.805 & $1.78(0.25-12.7)$ & 0.565 \\
\hline
\end{tabular}

variables with resistance. These findings are similar to a study which was carried out in Ethiopia [36] where they, as well, did not find a statistical association between the sociodemographic and clinical characteristics with resistance except for phenotypic and genotypic characteristics.

This study has limitations worth noting. Firstly, the study was liable to information bias due to social desirability and recall bias. However, this was controlled through validating medical records and through laboratory analysis. Secondly, we could not test all the drugs due to limited unavailability of some of the susceptibility drug discs as the research was not sponsored, hence limiting us to the drug discs available to the hospital at every given point.
However, although these limitations could have occurred, we think they did not significantly influence our findings. The results of this study remain important and add to the body of knowledge on the prevalence of AMR among pregnant women seeking antenatal care and associated factors in a low-resourced country like Zambia.

\section{Conclusion}

The UTI prevalence of $60 \%$ found among pregnant women in this study is generally much higher than most studies undertaken, which is indicative of the level of menace urinary tract infections in Zambia. This is 
alarming concern considering the adverse effects of untreated UTI on the mother and fetus such as kidney infections, preterm birth, low birth weight, and miscarriages. The highest causative agent of urinary tract infections was found to be E. coli which is another concern considering that it has the highest resistant strains which is resistant to the $3^{\text {rd }}$ generation cephalosporins implying that treatment of severe infections relies on carbapenems which are more expensive and might be a challenge for low-income countries. Furthermore, finding that the prevalence of antimicrobial resistance was at $53 \%$ with nalidixic acid, norfloxacin, and ampicillin being the most resistant is another concern considering that these drugs are commonly and routinely given, hence questioning treatment effectiveness.

Antimicrobial resistance results in this study additionally reflects the need for development of policies that restrict the usage of antibiotics and need to strengthen actions to ensure that antibiotics are used appropriately, such as reenforcing prescription-only policies, implementing surveillance of antimicrobial consumption, and implementing antimicrobial stewardship programs [35].

Furthermore, finding that sociodemographic characteristics were not associated with antimicrobial resistance in this study suggests need for conducting similar studies such as [20] that include examining genotypic and phenotypic characteristics.

\section{Abbreviations}

ATCC: American Type Culture Collection

AMR: Antimicrobial resistance

CLED: Cysteine-lactose-electrolyte-deficient

CDC: $\quad$ Centres for Disease Control and Prevention

DDD: Defined daily dose

E. coli: Escherichia coli

GP: $\quad$ General practice

LMUTH: Levy Mwanawasa University Teaching Hospital

WHO: World Health Organization

UTIs: $\quad$ Urinary tract infections.

\section{Data Availability}

The data used to support the findings of this study are available from the corresponding author upon request.

\section{Conflicts of Interest}

The authors declare that they have no conflicts of interest.

\section{Authors' Contributions}

KIY conceived and designed the experiments. KIY performed initial data collection and laboratory investigations. $\mathrm{KIY}, \mathrm{CJ}$, and CM contributed to refining the questions and study design and participated in data analysis and in writing of the manuscript. All the authors read and approved the manuscript.

\section{Acknowledgments}

The authors would like to acknowledge the institutional Biomedical Research Ethics Committee of the University of Zambia and the National Health Research Authority. They gratefully acknowledge the Levy Mwanawasa University Teaching Hospital for permission to carry out the research at their institution. They furthermore acknowledge their study participants for their kind cooperation.

\section{References}

[1] K. Gupta, T. M. Hooton, and W. E. Stamm, "Increasing antimicrobial resistance and the management of uncomplicated community-acquired urinary tract infections," Annals of Internal Medicine, vol. 135, pp. 41-50, 2010.

[2] J. H. Larcombe, Urinary Tract Infection in Women Aged 18-64: Doctors', Patients', and Lay Perceptions and Understandings, Durham University, Durham, UK, 2012.

[3] A. L. Demain and S. Sanchez, "Microbial drug discovery: 80 years of progress," The Journal of Antibiotics, vol. 62, no. 1, pp. 5-16, 2009.

[4] B. Getenet and T. Wondewosen, "Bacterial uropathogens in urinary tract infection and antibiotic susceptibility pattern in jimma university specialized hospital, southwest Ethiopia," Ethiopian Journal of Health Sciences, vol. 212 pages, 2011.

[5] T. Demilie, G. Beyene, S. Melaku, and W. Tsegaye, "Urinary bacterial profile and antibiotic susceptibility pattern among pregnant women in north west Ethiopia," Ethiopian Journal of Health Sciences, vol. 22, no. 2, pp. 121-128, 2012.

[6] R. G. Wax, K. Lewis, A. A. Salyers, and H. Taber, Bacterial Resistance to Antimicrobials, CRC Press, Boca Raton, FL, USA, 2007.

[7] B. T. Tadesse, E. A. Ashley, S. Ongarello, J. Havumaki, M. Wijegoonewardena, I. J. González, and S. Dittrich, Antimicrobial resistance in Africa: a systematic review," BMC Infectious Diseases (2017), vol. 17, p. 616, 2017.

[8] World Health Organization, Antimicrobial Resistance, World Health Organization, Geneva, Switzerland, 2014, http://www. who.int/mediacentre/factsheets/fs194/en.

[9] E. Melander, K. E. Md, G. J??Nsson, and S. M??Lstad, "Frequency of penicillin-resistant pneumococci in children is correlated to community utilization of antibiotics," The Pediatric Infectious Disease Journal, vol. 19, no. 12, pp. 11721177,2000

[10] W. Chavkin, V. Breitbart, D. Elman, and P. H. Wise, "National survey of the states: policies and practices regarding drug-using pregnant women," American Journal of Public Health, vol. 88, no. 1, pp. 117-119, 1998.

[11] J. Chisanga, M. L. Mazaba, J. Mufunda, C. Besa, M. C. Kapambwe-Muchemwa, and S. Siziya, "Antimicrobial susceptibility patterns and their correlate for urinary tract infection pathogens at Kitwe Central Hospital, Zambia," Health Press Zambia Bull, vol. 1, no. 1, pp. pp28-37, 2017.

[12] M. A. Belete, "Bacterial profile and esbl screening of urinary tract infection among asymptomatic and symptomatic pregnant women attending antenatal care of north western region," Infection and Drug Resistance, vol. 13, 2020.

[13] A. Derbie, D. Hailu, D. Mekonnen, B. Abera, and G. Yitayew, "Antibiogram profile of uropathogens isolated at bahir dar regional health research laboratory centre, northwest Ethiopia," Pan African Medical Journal, vol. 26, p. 134, 2017. 
[14] B. Derese, H. Kedir, Z. Teklemariam, F. Weldegebreal, and S. Balakrishnan, "Bacterial profile of urinary tract infection and antimicrobial susceptibility pattern among pregnant women attending at Antenatal Clinic in Dil Chora Referral Hospital, Dire Dawa, Eastern Ethiopia," Therapeutics and Clinical Risk Management 2016, vol. 12, pp. 251-260, 2016.

[15] M. A. Mohammed, T. M. S. Alnour, and O. M. Shakurfo, M. M. Aburass, Prevalence and antimicrobial resistance pattern of bacterial strains isolated from patients with urinary tract infection in Messalata Central Hospital, Libya," Asian Pacific Journal of Tropical Medicine, vol. 9, no. 8, pp. 771-776, 2016.

[16] Clinical Laboratory Standards Institute (CLSI), "Performance standards for antimicrobial susceptibility testing," Twentyfourth informational supplement. CLSI document M100-S24, vol. 34, pp. 50-57, Clinical and Laboratory Standards Institute, Wayne, PA, USA, 2014.

[17] A. A. Al-Naqshbandi, M. A. Chawsheen, and H. H. Abdulqader, "Prevalence and antimicrobial susceptibility of bacterial pathogens isolated from urine specimens received in rizgary hospital-Erbil," Journal of Infection and Public Health, vol. 12, no. 3, pp. 330-336, 2019.

[18] M. Kibret and B. Abera, "Prevalence and antibiogram of bacterial isolates from urinary tract infections at Dessie Health Research Laboratory, Ethiopia," Asian Pacific Journal of Tropical Biomedicine, vol. 4, no. 2, pp. 164-168, 2014.

[19] J. G. Bradley, A. J. Stewardson, I. J. Abbott, and Y. P. Anton, "Nitrofurantoin and fosfomycin for resistant urinary tract infections: old drugs for emerging problems," Australian Prescriber, vol. 42, no. 1, pp. 14-19, 2019.

[20] L. Valiquette, "Urinary tract infections in women," The $\mathrm{Ca}$ nadian Journal of Urology, vol. 8, pp. 6-12, 2001.

[21] S. Ahmad, "Pattern of urinary tract infection in Kashmir and antimicrobial susceptibility," Bangladesh Medical Research Council Bulletin, vol. 38, no. 3, pp. 79-83, 2012.

[22] C. O. Stanley, "Prevalence and antimicrobial susceptibility pattern of urinary tract infection (UTI) among pregnant women in afikpo, Ebonyi state, Nigeria," American Journal of Life Sciences, vol. 2, no. 2, pp. 46-52, 2013.

[23] N. U. Adabara, J. A. Momoh, J. D. Bala, A. A. Abdulrahaman, and M. B. Abubakar, "The prevalence of bacterial urinary tract infections (uti) among women attending antenatal clinic in the general hospital, minna in Niger state," International Journal of Biomedical Research, vol. 3, no. 03, pp. 171-173, 2012.

[24] M. A. Jazayeri and G. H. R. Irajian, "Asymptomatic urinary tract infection in pregnant women," Iranian Journal of $\mathrm{Pa}$ thology, vol. 4, pp. 105-108, 2009.

[25] D. Marami, S. Balakrishnan, and B. Seyoum, "Prevalence, antimicrobial susceptibility pattern of bacterial isolates, and associated factors of urinary tract infections among HIVpositive patients at hiwot fana specialized university hospital, eastern Ethiopia," Canadian Journal of Infectious Diseases and Medical Microbiology, vol. 2019, p. 8, 2019.

[26] M. A. Ahmed, G. S. Shukla, and H. Kumar Bajaj, "Incidence of urinary tract infections and determination of their susceptibility to antibiotics among pregnant women attending antenatal at Sri Vijaya hospital at mehdipatnam, Hyderabad city India," International Journal of Cell Science and Biotechnology, vol. 5, 2016.

[27] J. Akerele, P. Abhulimen, and F. Okonofua, "Prevalence of asymptomatic bacteriuria among pregnant women in Benin City, Nigeria," Journal of Obstetrics and Gynaecology: The Journal of the Institute of Obstetrics and Gynaecology, vol. 21, no. 2, pp. 141-144, 2001.
[28] Escherichia coli (E. coli), "Mother to baby," 2019, http://www. mothertobaby.org/.

[29] Y. Ling, J. Yu, H. Hongdong, and B. Yan, "The association between urinary tract infection during pregnancy and preeclampsia (China)," Medicine, vol. 97, p. 36, 2018.

[30] A. C. Mirella, L. M. A. Gabriela, M. M. Iara, and R. F. Marise, "Antibiotic resistance patterns of urinary tract infections in a northeastern brazilian capital," Revista do Instituto de Medicina Tropical de Sao Paulo, vol. 58, p. 2, 2016.

[31] I. P. Ade-Ojo, A. O. Oluyege, P. T. Adegun, A. A. Akintayo, O. P. Aduloju, and B. A. Olofinbiyi, "Prevalence and antimicrobial suseptibility of asymptomatic significant bacteriuria among new antenatal enrollees in Southwest Nigeria," International Research Journal of Microbiology, vol. 4, no. 8, pp. 197-203, 2013.

[32] R. Onoh, O. U. J. Egwuatu, P. Ezeonu, T. Onoh, and O. Umeora, "Antibiotic sensitivity pattern of uropathogens from pregnant women with urinary tract infection in Abakaliki, Nigeria," Infection and Drug Resistance 2013, vol. 6, pp. 225-233, 2013.

[33] M. R. Judith, N. Pasiponadya, O. H. Clara, and S. P. Babill, "Antibiotic susceptibility of bacterial strains causing asymptomatic bacteriuria in pregnancy: a cross-sectional study in harare, Zimbabwe," Immunology, vol. 61 page, 2018.

[34] K. C. Ekwedigwe, I. Sunday-Adeoye, M. O. Eliboh et al., "Prevalence and antimicrobial susceptibility of asymptomatic bacteriuria among women with pelvic organ prolapse in Abakaliki, South-East Nigeria," BMC Women's Health, vol. 18, p. 53, 2018.

[35] WHO, WHO Report on Surveillance of Antibiotic Consumption, WHO, Geneva, Switzerland, 2018.

[36] Z. Gizachew and K. Tesfaye, G. Beyene, R. Howe, and Y. Biruk, Multi-drug resistant bacteria and associated factors among reproductive age women with significant bacteriuria," Ethiopian Medical Journal, vol. 2019, no. 1, 2019.

[37] M. Sekikubo, K. Hedman, F. Mirembe, and A. Brauner, "Antibiotic overconsumption in pregnant women with urinary tract symptoms in Uganda," Clinical Infectious Diseases, vol. 65, no. 4, pp. 544-550, 2017. 